tends a distance of four inches, and is bridged over in its last twelfth of an inch, so as to form a canal for the reception of a delicate whalebone guide. The catheter eye is on the concave side of the instrument, about three-fourths of an inch from its point, and is kept closed by a well-fitted stylet.

The curve of the instrument is equal to one-fifth of the circumference of a circle three inches and a quarter in diameter.

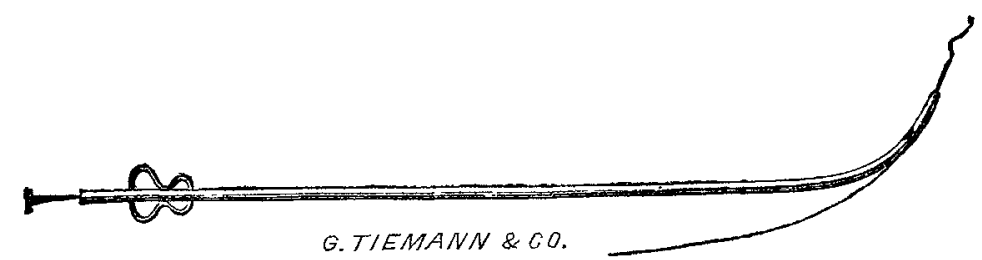

The manner of using it is as follows. With a small syringe the urethra is to be filled with olive oil, and an attempt made to introduce a probe-pointed whalebone guide, half a millimeter in diameter, and of the length of an ordinary bougie, the point of which may be made temporarily spiral by immersion in boiling water, then twisting around a small staff, and suddenly cooling it. If its point becomes engaged in a lacuna, it is to be withdrawn a little, and again carried onward with a rotary movement. If it enters a false passage, it is to be retained in situ by the left hand, while another is passed by its side. If this second guide makes its way into the false passage, it is to be treated precisely as the first was, and the operation repeated till one guide can be made to pass the obstruction, and enter the bladder. Sometimes five or six guides are thus caught before the false passage is filled up, and the natural route opened. As soon as the bladder is entered by a guide-which may be known by the instrument being easily moved in and out-the other guides are to be with drawn, the free end of the retained guide passed through the canal at the end of the catheter, and this instrument carried down the urethra along the guide until its point reaches the stricture. Generally, with slight pressure in the right direction, the catheter may be made to enter the stricture, and finally pass into the bladder.

The guide may be kept in position after the withdrawal of the catheter, and dilatation carried on by the successive introduction of larger-sized catheters of the same construction; or divulsion may be resorted to by means of Mr. Holt's or Sir Henry Thompson's instrument, modified by means of the terminal canal for the passage of the guide; or internal urethrotomy may be practised with any of the various urethrotomes, having only this simple modification or, as has already on several occasions been done, the retention catheter may be made available in external urethrotomy, instead of Mr. Syme's staff.

New York, April, 1869.

\section{A CASE OF POISONING BY NICOTIANA.} By MAURICE G. EVANS, M.D., M.R.C.S.

The following case of poisoning by nicotiana may perhaps, on account of the manner in which it was produced, prove interesting and instructive. I was summoned on the 21st instant to see a little boy, seven years of age, said to be in a fit. On arriving at the house, I found him completely insensible, cold, pulseless, with prolonged respiration. On trying to rouse the child, I discovered a blackish patch, about the size of the palm of the hand, on the side of his neck, which I was informed was ringworm, and that an ever-ready old woman prescriber, with which this neighbourhood is blessed, had advised the parents to procure an old much-used tobacco pipe, to scrape its interior, and apply the ash, mixed with a little oil, to the abraded surface. In the course of half an hour the child went to his father complaining of a sense of choking, tottering in his gait, and vomiting. I saw him about twenty minutes after, and found him in the state above described. The father assured me the quantity of ash applied could be held on the point of a tolerable-sized penknife. The treatment pursued was, having the part immediately well washed with soap and water, rousing the little patient, administering ammonia and coffee, with friction to the limbs, \&c. Consciousness and reaction soon commenced returning, and in an hour or so the child was out of danger.

Narberth, May, 1869.

\section{Af aflitror}

OF THE PRACTICE OF

\section{MEDICINE AND SURGERY IN THE}

\section{HOSPITALS OF LONDON.}

Nulla autem est alia pro certo noscendi via, nisi quamplurimas et morborum t dissectionum historias, tum aliorum, tum proprias collectas habere, et inter se comparare.-Morgagni De Sed. et Caus. MTorb., lib. iv. Proœminm.

\section{GUY'S HOSPITAL.}

CASE OF TETANUS, RAPIDLY FATAL.

(Under the care of Mr. JoHN BiRketr.)

IT fortunately happens that tetanus rarely causes death so quickly as in the following case. The probabie explanation of the man's rapid dissolution is to be found in the depressed and worn condition of his general constitutional powers. Very little time was afforded to allow the medicines administered to exert their influence, and, in fact, they produced no appreciable effect whatever. The spasms commenced, as usual, in the muscles of the neck and jaw, on the fifth day after the infliction of the injury; and so rapidly did the disease progress that the man survived its first indications little more than twenty-four hours.

J. $\mathrm{H} \longrightarrow$, aged fifty-seven, was admitted into a private room in Guy's Hospital on the 10th February, 1869. He then stated that he had crushed his left index-finger between two ropes, producing a compound fracture of the first phalanx, on the 4th February. On the 8th and 9th he attended at the surgery to have the finger dressed; and in the evening of the 9th, the fifth day after the injury, he felt stiffness of his neck, and his jaw became rigid. $\mathrm{He}_{\mathrm{e}}$ had taken no solid food for four days.

Feb. 10th.-9.30 A.m.: When admitted he was able to walk with a little assistance; was perfectly sensible; his countenance had a peculiar fixed expression; his jaws were rigid and fixed, with a piece of wood between the teeth his head was drawn back, but there was no contraction of other muscles. He was at once put to bed.-11.15 A.Mr.: He has difficulty in swallowing; complains of pain in the small of his back, which is from time to time slightly arched by the contraction of its muscles. Pulse 80 ; respiration 24. He was ordered a solution of extract of Calabar bean in water, neutralised with liquor ammoniæ, for subcutaneous injection; and at noon five minims, containing one-sixth of a grain of the extract, was injected beneath the skin of the arm. To be fed with beef-tea, milk, and brandy.1.40 P.Mr. : Has made two attempts to drink, each of which brought on spasms threatening suffocation. Pupils of normal size.-2 P.M. : One-third of a grain of the extract was injected as before. Pulse 110, full and jerking; respiration 34, irregular; expiration noisy; he has slept a little; has slight spasms every six or seven minutes; the masseters and muscles of the back of the neck are continually contracted; he keeps hawking up rather viscid saliva, and is in a profuse sweat.-4 P.Mr.: One-third of a grain of the extract was injected. A quarter of an hour afterwards the muscles of the back and thighs contracted strongly; pupils are not much contracted.-5 P.M. : One-third of a grain of extract. Being unable to swallow, he had an enema of beef-tea, opium, and starch.-7.45: Had a severe spasm, lasting two minutes, when he was almost exhausted. During that time the pulse rose to 140 ; respiration $40 .-8.30$ : Half a grain of extract injected. Spasm of three minutes, in which the respiration was chiefly affected. Enema of beef-tea repeated.-10 P.M. : One-third of a grain of the extract of Calabar bean, with one-third of a grain of morphia.-11 p.Mr. : 'Two-thirds of a grain of the extract. Spasms frequent, almost continuous. 